\title{
78. An Improved Sulphide Silver Method using Hydroquinone Derivatives in Physical Developer
}

\author{
By Mitsuo Nakamura,*) Osamu FuJimorI,*) Shigetada FUJII,**) \\ and Tatsuo SHIMADA*)
}

(Communicated by Teizo Ogawa, M. J. A., Dec. 13, 1982)

The sulphide silver method for the histochemical detection of heavy metals was established by Timm. ${ }^{1)}$ In this method, tissues are fixed in $\mathrm{H}_{2} \mathrm{~S}$-saturated fixatives and tissue sections subjected to physical development. For the latter process, the developer established by Lüppo-Cramer ${ }^{2)}$ or its modifications ${ }^{3)-8)}$ have traditionally been employed. However, the use of hydroquinone as a reductant caused a weak activity of these developers. A series of our current experimentations have shown that certain derivatives of hydroquinone gave better results than hydroquinone itself. It has further been noted that the protective effect of gum arabic for the developer is greatly enhanced, if the supernatant of the ultracentrifuged reagent is employed. In the present study, the newly devised developer containing both these reagents was used in comparison with the Lüppo-Cramer and Timm's developer. ${ }^{1), 2)}$ The results obtained with a series of metal containing tissues indicated a higher sensitivity of former developer, as compared with the latter.

Materials and methods. Animals: Male adult rats of Wister strain were employed. Staining procedures: Animals were perfused for 10 min with phosphate-buffered ( $\mathrm{pH}$ 7.4) $3 \%$ glutaraldehyde$4 \%$ paraformaldehyde solution saturated with $\mathrm{H}_{2} \mathrm{~S}$. After perfusion, tissues such as the brain, pancreas, duodenum and prostate gland were excised and immersed in the same fixative for $4 \mathrm{hr}$. Some other animals were perfused for 10 min with the ungassed glutaraldehydeparaformaldehyde fixative. The four types of tissues were immersed in the $\mathrm{H}_{2} \mathrm{~S}$ free fixative for $4 \mathrm{hr}$. All the tissue specimens were then washed for about $36 \mathrm{hr}$ in running tap water, dehydrated in ethanol, cleared in xylene and embedded in paraffin. 4 micra thick sections were made and mounted on glass slides. The sections were deparaffinized, hydrated and then treated with the Lüppo-Cramer and Timm's (LCT) or the present improved (PI) developer. (1) Procedure with LCT developer. Formula of LCT developer. Solu-

*) Department of Anatomy, Medical College of Oita.

**) Division of General Education, Medical College of Oita. 
tion A : $20 \%$ gum arabic solution, $50 \mathrm{ml} ; 10 \%$ silver nitrate solution, $1 \mathrm{ml}$. Solution B: Hydroquinone, $200 \mathrm{mg}$; citric acid, $500 \mathrm{mg}$; distilled water, $10 \mathrm{ml}$. The working solution is prepared by mixing solutions A and B in complete darkness immediately before use. Sections were developed for $60 \mathrm{~min}$ at $23^{\circ} \mathrm{C}$ in daylight. They were then washed and counterstained with hematoxylin-eosin (HE). (2) Procedure with PI developer. Formula of PI developer. Solution A: Supernatant of $20 \%$ gum arabic solution ultracentrifuged at 24,000 $\times \mathrm{G}$ for $1 \mathrm{hr}, 50 \mathrm{ml} ; 10 \%$ silver nitrate solution, $1 \mathrm{ml}$. Solution B: Bromohydroquinone, $200 \mathrm{mg}$; hydroxy-hydroquinone, $2 \mathrm{mg}$; citric acid, $300 \mathrm{mg}$; distilled water, $10 \mathrm{ml}$. The working solution is prepared as in the LCT developer. Sections were developed for $60 \mathrm{~min}$ at $20^{\circ} \mathrm{C}$ in complete darkness. They were then washed and counterstained as in the procedure (1). In both (1) and (2) procedures, (a) tissues fixed in an $\mathrm{H}_{2} \mathrm{~S}$-saturated fixative and (b) those fixed in an $\mathrm{H}_{2} \mathrm{~S}$ free fixative were examined, respectively in attempts to detect (a) the general patterns and intensities of the stainings and (b) the presense of tissue components which can attract silver ions without preceding sulphide-liking procedure. After development, all the tissue sections were washed in water, dehydrated in ethanol, cleared in xylene and mounted in Biolite.

Results. 1) Results obtained with LCT developer. (a) Tissues fixed in $\mathrm{H}_{2} \mathrm{~S}$-saturated glutaraldehyde (GA)-paraformaldehyde (PFA) and treated with LCT developer: In the brain tissue, microscopic observations were focussed upon the hippocampal formation. In this structure, the positive sulphide silver (SS) reaction of varying intensities was found to be distributed in zonal patterns which correspond to those defined neurohistologically (Fig. 1). Of these reactive zones, the mossy fiber layer was the strongest in intensity of the reaction. In the pancreas, the cytoplasm of the insular cells was seen to exhibit moderately positive SS reaction (Fig. 2). In the duodenum, the cytoplasmic granules of Paneth cells were found to show intensely positive SS reaction (Fig. 3). In the prostate gland, the SS reaction of the secretory granules in the glandular cells and luminal secretions was moderate in intensity (Fig. 4). (b) Tissues fixed in $\mathrm{H}_{2} \mathrm{~S}$-free GA-PFA and treated with LCT developer: In four types of tissues, the silver reaction was seen to be negative without exception.

2) Results obtained with PI developer. (a) Tissues fixed in $\mathrm{H}_{2} \mathrm{~S}$-saturated GA-PFA and treated with PI developer: In all the zones of hippocampal formation of the brain tissue, the positive SS reaction was found to be apparently stronger in intensity than that observed in those developed by the LCT developer (Fig. 5). In the 
Figs. 1-8. 1: Rat hippocampal formation fixed in $\mathrm{H}_{2} \mathrm{~S}$-saturated GA-PFA, treated with LCT developer and counterstained with $\mathrm{HE} . \times 15$. 2 : Rat pancreas fixed in $\mathrm{H}_{2} \mathrm{~S}$-saturated GA-PFA, treated with LCT developer and counterstained with $\mathrm{HE} . \times 61$. 3 : Rat duodenum fixed in $\mathrm{H}_{2} \mathrm{~S}-$ saturated GA-PFA, treated with LCT developer and counterstained with HE. $\times 61$. 4: Rat prostate gland fixed in $\mathrm{H}_{2} \mathrm{~S}$-saturated GA-PFA, treated with LCT developer and counterstained with $\mathrm{HE}$. $\times 31$. 5: Rat hippocampal formation fixed in $\mathrm{H}_{2} \mathrm{~S}$-saturated GA-PFA, treated with PI developer and counterstained with $\mathrm{HE} . \times 15$. 6: Rat pancreas fixed in $\mathrm{H}_{2} \mathrm{~S}$-saturated GA-PFA, treated with PI developer and counterstained with HE. $\times 61$. 7: Rat duodenum fixed in $\mathrm{H}_{2} \mathrm{~S}$-saturated GA-PFA, treated with PI developer and counterstained with HE. $\times 61$. 8: Rat prostate gland fixed in $\mathrm{H}_{2} \mathrm{~S}$-saturated GA-PFA, treated with PI developer and counterstained with $\mathrm{HE} . \times 31$.

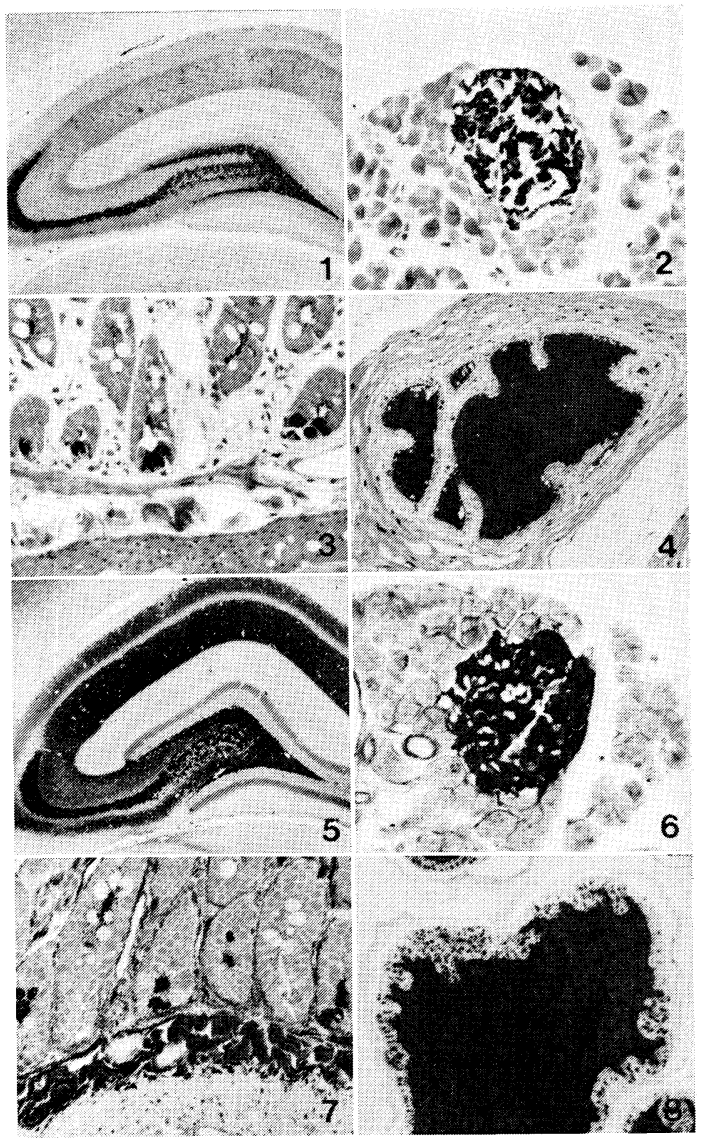

pancreas, the SS reaction of the cytoplasm of the insular cells was of an extreme intensity (Fig. 6). In the duodenum, the SS reaction of the cytoplasmic granules of Paneth cells was distinctly marked in intensity (Fig. 7). In addition to this, the subepithelial connective tissue elements were shown to exhibit moderately positive SS reaction (Fig. 7). In the prostate gland, the positive SS reaction of both the secretory granules in the glandular cells and luminal secretions was marked in intensity (Fig. 8). (b) Tissues fixed in $\mathrm{H}_{2} \mathrm{~S}$ free GA-PFA and treated with PI developer: In the brain, pancreas and duodenum tissues, the silver $(\mathrm{S})$ reaction was found to be negative. In contrast, the luminal secretions of the prostate gland were found to exhibit markedly positive $\mathrm{S}$ reaction. In all the tissues treated with PI developer $(a, b)$, background stainings due to false precipitations of silver were suppressed to minimum, even though the sensitivity of the SS reaction was vividly high.

Discussion. In the four types of tissues, the positive SS reactions obtained by treatment with the present improved (PI) developer 
are found to be apparently stronger in intensity than those visualized by treatment with the Lüppo-Cramer-Timm's (LCT) developer. Thus, it is certain that the SS method using the PI developer is significantly more sensitive than that employing the LCT developer. Such higher sensitivity of the methods using the PI developer may be explained mainly by the higher developing activity of hydroquinone derivatives as compared with hydroquinone.") According to the results obtained in $1 \mathrm{~b}$ ) and $2 \mathrm{~b}$ ), the $\mathrm{S}$ reaction with the PI developer in the prostatic secretions treated with $\mathrm{H}_{2} \mathrm{~S}$ free fixative was strongly positive. Like the present prostatic secretions, the tissue components exhibiting positive $\mathrm{S}$ reaction are collectively designated as primary germs ${ }^{101.11)}$ which have been confirmed in pathological tissues. ${ }^{8), 10), 12)-}$ 1.i) The above results are taken to represent the first primary germ discovered in the normal organs of adult mammals. The nature of the primary germ observed here remains to be elucidated. In the tissues stained by the SS method using PI developer, background stainings due to false precipitations of silver were suppressed to minimum, despite the high sensitivity of the method.

Taken altogether, the sulphide silver method using the present improved developer may be concluded to be a reliable technique of choice, since its sensitivity and precipitation selectivity are greatly improved as compared with analogous methods hitherto used.

Acknowledgements. We are grateful to Professor Emeritus, Dr. Teizo Ogawa, M.J.A., for criticism and improvement of the manuscript with valuable advice. And also our thanks are due to Dr. Tsuneo Suga, Konishiroku Photo Industry Company for advices about the theory of photographic chemistry.

\section{References}

1) Timm, F.: Deut. Z. gericht. Med., 46, 706-711 (1958).

2) Lüppo-Cramer: Photographische Korrespondenz Nr., 640, 28-34 (1914).

3) Voigt, G. E.: Virchows Arch. Path. Anat., 332, 295-323 (1959).

4) Pihl, E., and Falkmer, S.: Acta histochem., 27, 1-6 (1967).

5) Pihl, E.: Histochemie, 10, 126-139 (1967).

6) Müller, A., and Geyer, G.: Acta histochem., 31, 98-110 (1968).

7) Haug, F.-M. S.: Adv. Anat. Embryol. Cell Biol., 47, 1-71 (1973).

8) Danscher, G.: Histochemistry, 71, 1-16 (1981).

9) James, T. H.: The Theory of Photographic Process (ed. James, T. H.). Macmillan, N. Y., pp. 291-334 (1977).

10) Voigt, G. E.: Z. f. wissenschaftliche Mikroskopie u. f. mikrosk. Technik, 61, 1-8 (1952).

11) Brunk, U., Brun, A., and Sköld, G.: Acta histochemica, 31, 345-357 (1967).

12) Timm, F., und Arnold, M.: Naunyn-Schmiedeberg's Arch. exp. Path. Pharmak., 239, 393-399 (1960).

13) Danscher, G.: Histochemistry, 71, 81-88 (1981).

14) —-: ibid., 71, 177-186 (1981).

15) Danscher, G., and Schrøder, H. D.: ibid., 60, 1-7 (1979). 